\title{
The crystal packing and slip plane analysis in mechanical properties improvement of mefenamic acid by cocrystallization with nicotinamide coformer
}

\author{
Ari Wahyudi ${ }^{\mathrm{a}}$, Dwi Utami ${ }^{*}$, Arif Budi Setianto ${ }^{\mathrm{c}}$ \\ ${ }^{a}$ Magister student of Postgraduate Program, Faculty of Pharmacy, Universitas Ahmad Dahlan, Yogyakrta 55164, Indonesia \\ ${ }^{b}$ Department of Analytical and Medicinal Chemistry, Faculty of Pharmacy, Universitas Ahmad Dahlan, Yogyakrta 55164, Indonesia \\ ${ }^{3}$ Department of Pharmaceutical Technology, Faculty of Pharmacy, Universitas Ahmad Dahlan, Yogyakrta 55164, Indonesia
}

Article history:

Received: 7 October 2020 / Received in revised form: 29 November 2020 / Accepted: 30 November 2020

\begin{abstract}
Mefenamic acid is an analgesic non-steroidal anti-inflammatory drug (NSAID) that is categorized as Biopharmaceutical Classification System (BCS) class II drug. Cocrystallization of mefenamic acid (MFA) with nicotinamide (NIC) has been reported to enhance the solubility of MFA for about 2.56 times higher than pure MFA. As a part of MFA-NIC development in pharmaceutical dosage form, we reported the improvement of mechanical properties of MFA-NIC cocrystal based on the presence of slip planes in crystal structure. The research was initially by synthesizing and characterizing the cocrystal by using X-ray diffraction analysis, and was followed by the investigation of the mechanical properties of MFA and its cocrystal, i.e. tensile strength and deformation parameter. The correlation of crystal structure with mechanical properties was determined by crystal packing motif and slip plane analysis from single crystal data by using Mercury 3.6. The tensile strength of MFA was acceptance at 20.0 MPa, and dropped at more than 25.0 MPa. A better tableting performance was observed in MFA-NIC cocrystal which had the tensile strength 1.5 times higher than MFA at $12.5 \mathrm{MPa}$ and gradually increased with an increasing pressure up to 2.5 times at 22.5 MPa. The flat slip plane of MFA-NIC cocrystal was predicted as the key factor in the improvement of its mechanical properties, compared to zigzag slip plane of MFA. In conclusion, MFA-NIC cocrystal had the better mechanical properties than pure MFA due to its flat slip plane and it becomes potential to be explored in further development of solid dosage form.
\end{abstract}

Keywords: Mefenamic acid; cocrystal; mechanical properties; slip plane

\section{Introduction}

In the last decade, crystal engineering in solid-state material is getting popular, particularly in active pharmaceutical ingredient [1-4]. Cocrystal as one of the crystal engineering is chosen as a potential strategy due to its advantages in solid-state physicochemical properties such as solubility, bioavailability, mechanical properties, and stability [5-10].

Commonly, the development of pharmaceutical cocrystal aims to improve the solubility of drugs classified in Biopharmaceutics Classification System (BCS) class II (low solubility, high permeability). There are many pharmaceutical cocrystals that successfully improve the solubility of its parent drugs [11-12]. In the crystallographic insight, the alteration of its solubility properties is an impact of crystal structure differences in the presence of conformer. The alteration of crystal structure influences not only the solubility properties but also its mechanical properties. Some researchers investigated a relationship between crystal structure and mechanical properties [13-20]. Kale et al. reported a better tableting performance of rivaroxaban-malonic acid (2:1)

* Corresponding author. Tel.:+62-274-563515; fax:+62-274-564604.

Email: dwi.utami@pharm.uad.ac.id cocrystal than that of rivanoxaban due to the presence of flat slip plane that enhances the plasticity of rivaroxaban-malonic acid cocrystal [21].<smiles>Cc1cccc(Nc2ccccc2C(=O)O)c1C</smiles>

(a)<smiles>O=C(O)c1cccnc1</smiles>

(b)
Fig. 1. The chemical structure of MFA (a), and NIC (b)

To continue to improve the solubility of the current cocrystal, herein we reported the performance of the mechanical properties of mefenamic acid (MFA) : nicotinamide (NIC) cocrystal. Mefenamic acid (Fig.1) is an anti-inflammatory agent that belongs to BCS class II with low solubility properties [22]. Fabian et al. synthesized and solved the crystal structure of MFA-NIC cocrystal [23]. In line with the aims of cocrystal development, it is important to explore 
the physical-chemical properties alteration of MFA due to cocrystallization, particularly solubility and mechanical properties required in further solid state dosage form development of MFA-NIC cocrystal. To the best of our knowledge, this is the first study that reported the improvement of mechanical properties of MFA in the MFANIC cocrystal form, after the better solubility alteration for about 2.56 fold higher than MFA that have been reported by Utami et al [24]. Despite that, to enhance a relationship between crystal structure and mechanical properties, we discussed the improvement of the mechanical properties of its cocrystal from crystallographic insight, i.e. slip plane and slip plane topology.

It has been shown that crystal structure, particularly slip planes, can profoundly influence the compaction properties of pharmaceutical cocrystals [13-20]. Slip planes are crystallographic planes that have the weakest interplanar interaction in a given crystal and have been associated with the highest molecular density and the largest separation between adjacent planes [14]. The presence of slip planes in crystal structure facilitates sliding motion, hence providing greater plasticity to the crystal and resulting in an increased inter-particulate bonding area of the compact [25].

The mechanical properties of both MFA and MFA-NIC cocrystals have been studied using tensile strength measurements. The differences in the compaction properties of the two crystals were observed and followed by crystal packing and slip plane analysis using the crystal structure stored at Cambridge Structural Database (CSD). This study was also as a part of MFA-NIC cocrystal development as potential solid-state material in solid dosage form.

\section{Materials and Methods}

The active compound was obtained from Pyridam $(99.0 \%$ Pyridam of mefenamic acid) and nicotinamide (95\% EMerck).

\subsection{Cocrystal preparation and characterization}

The MFA-NIC cocrystal was produced by neat grinding method as reported by Fabian et al. (2011). The cocrystal characterization was assessed by Powder X-ray diffraction (PXRD) with the following conditions: target/filter (Monochromatic) with the help of $50 \mathrm{kV}$, current $30 \mathrm{~mA}$, slit wide 0.2 inches, data obtained by scanning $0.2^{\circ}-0.5^{\circ}$ per minute using distance scanning $2 \theta=5^{\circ}-40.5^{\circ}$.

\subsection{Mechanical properties experiment}

Tablet ability test. MFA Powder, MFA - NIC physical mixture (PM) and MFA - NIC cocrystal each of which weighed $500 \mathrm{mg}$, were molded using carver hydraulic of 0.25 , $0.5,0.75,1,1.25,1.5,1.75,2,2.25,2.5,2.75,3$ tons of pressure. The produced tablet was stored at $27^{\circ} \mathrm{C}$ with a humidity of $60 \%$ for 24 hours, followed by measuring the solidity and making a graph on the relation between tensile strength with compression pressure to compare the tabletability properties.

Elastic recovery (ER) test. MFA powder, MFA - NIC physical mixture and MFA - NIC cocrystal, each of which weighed $500 \mathrm{mg}$, were molded using carver hydraulic of 0.25 , $0.5,0.75,1,1.25,1.5,1.75,2,2.25,2.5,2.75,3$ tons of pressure. The diameter and thickness of the produced tablet were measured, and stored at $27^{\circ} \mathrm{C}$ with the humidity of $60 \%$ for 24 hours, and followed re-measuring its diameter and thickness. The porosity parameter was presented as Elastic Recovery (ER).

\subsection{Crystal packing and slip plane analysis}

The crystal packing and slip plane of MFA-NIC cocrystal were analyzed from single crystal X-ray diffraction from CSD with code EXAQOK. The MFA-NIC crystal structure was determined visually to identify the crystal packing and slip plane of its molecule by using Mercury CSD (V.3.10, The Cambridge Crystallographic Data Centre (CCDC), Cambridge, UK). The crystal packing was presented as intra and intermolecular interaction of each molecule. Whether the slip plane was identified as region that none of absence of hydrogen bond or other molecular interactions are present. The pattern of slip plane was presented as red ribbon along crystal packing. This process was also done to MFA single crystal with CSD code XYANAC.

\section{Results and Discussion}

\subsection{MFA-NIC cocrystal preparation}

The MFA-NIC powder preparation was done by grinding what was previously reported by Fabian et al. [23]. The cocrystal characterization was assessed by PXRD - a powerful tool in crystal structure alteration detection of solid material [26-28]. The PXRD profiles of MFA, NIC, physical mixture of MFA-NIC and its cocrystal were different from those of MFA and NIC. The new diffraction peak was observed in 2 e: 12.3 as the specific diffratogram of MFA-NIC cocrystal [23].

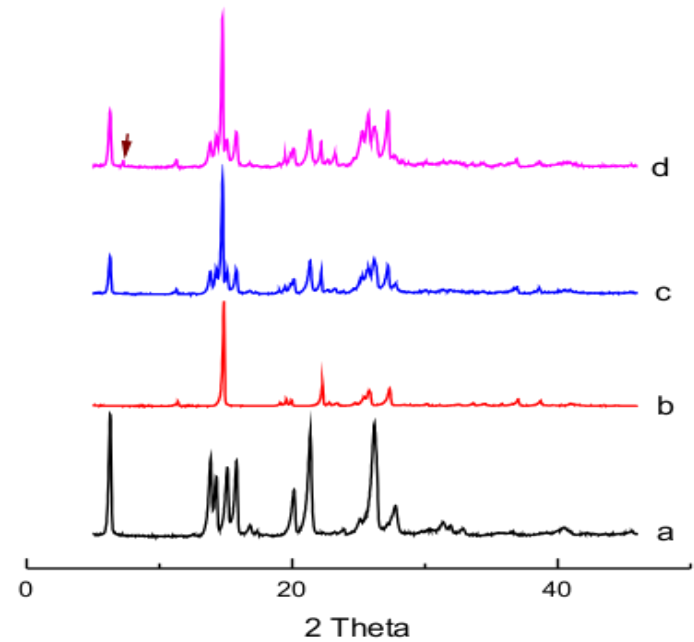

Fig. 2. The powder X-ray diffraction pattern of MFA (a), NIC (b), physical mixture of MFA-NIC (c), and cocrystal of MFA-NIC (d)

\subsection{The mechanical properties}

Tabletability is defined as the capacity of the powder material to be transformed into a tablet of specified tensile strength or the ability of a material to solidify when it receives 
external pressure [19]. This ability is required in tablet formation. Poor tabletability will cause certain problems in a series of processes, especially in tablet manufacturing. An excellent tabletability performance will help drug preparations in tablet form. The tabletability of a substance can be represented by a plot of tensile strength versus compression stress. A high tabletability performance of bulk material is presented as high tensile strength at low compression [29].

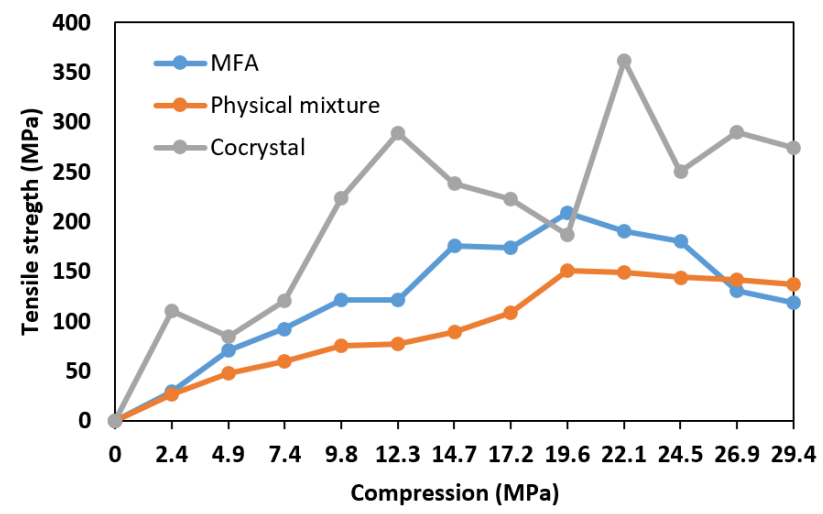

Fig. 3. The tensile strength result of MFA, MFA-NIC physical mixture and MFA-NIC cocrystal

Fig. 3 presents the tabletability of bulk material MFA dan MFA-NIC cocrystal. The tensile strength of all bulk materials increased with the increase of the compression pressure from 5 to $20 \mathrm{MPa}$. However, at the higher compressive stress strength, the tensile strength decreased, due to maximum plastic deformation. The highest tensile strength of MFA-NIC was achieved in $12.5 \mathrm{MPa}$, whether MFA in $20.0 \mathrm{MPa}$. The tabletability order based on the tensile strength at the higher compaction pressure follows the order MFA < PM MFA-NIC $<$ MFA-NIC cocrystal.

The tensile strength of the compacts is governed by interparticule bonding area and bonding strength [19]. The increase of bonding area is achieved on irreversible (plastic deformation) known as plasticity. The crystallographic features such as slip systems are responsible for plasticity $[15,17]$. There in further, the higher tabletability of MFA-NIC cocrystal compared to MFA will be discussed from the slip planes system of both.

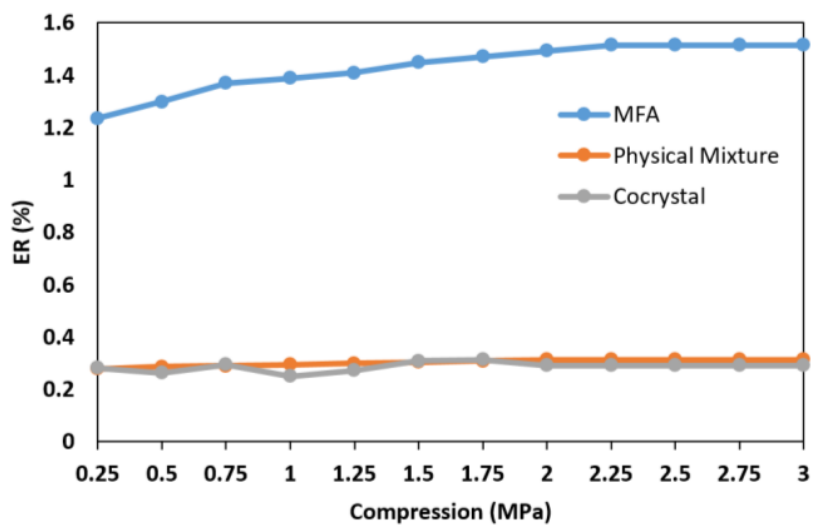

Fig. 4. The elastic recovery result of MFA, MFA-NIC physical mixture and MFA-NIC cocrystal
Moreover, the mechanical properties of all solid materials were also assessed in porosity parameter as elastic recovery (ER). Porosity has been linked with one of the volume reduction mechanisms of powders. The measurement of relative difference in porosity can provide information about the extent of plastic deformation of the powder bed during compression. The relatively high elastic recovery (ER) of all bulk materials is shown in Fig. 4. MFA at a pressure of 2.45 MPa showed an ER value of $1.25 \%$; at the same pressure, PM revealed an ER value of $0.27 \%$; while the ER value in cocrystal was $0.28 \%$.

According to elastic recovery result, MFA had low tabletability and a high ER value describing a porous tablet was weak in strength. MFA-NIC physical mixture had a low tabletability value and a low ER value, indicating that it was thick, not porous, but weak in strength, while the cocrystal had high tabletability and low ER value. This finding indicated that MFA-NIC cocrystal had better mechanical properties than MFA. In addition, MFA-NIC cocrystal is recommended to compress tablets at a pressure of $12.25 \mathrm{Mpa}$ to provide optimal hardness and fulfil the standard range of tablet hardness. Moreover, the inter-particulate bonding strength of MFA-NIC cocrystal was higher than that of MFA, supported by elastic recovery properties of post-compression tablets with a lower value when compared to MFA.

\subsection{Crystal packing and slip plane analysis}

Furthermore, as stated previously, the mechanical properties of solid-state material is correlated with its crystal structure. Therefore in this research, we explored the crystal structure of MFA and MFA-NIC cocrystal and identified the present topology of slip plane.

Table 1 presents the topology of slip plane of MFA and MFA-NIC cocrystal. The detail of slip plane topology of MFA is shown in Fig 5. The MFA single crystal lattice had the weakest plane parallel to (001), which allowed the zigzag slip plane. This structure indicated that it was difficult for the molecule to carry out lateral displacement due to the limitations of the folds of the molecule. Consequently, the MFA had a low tablet strength.

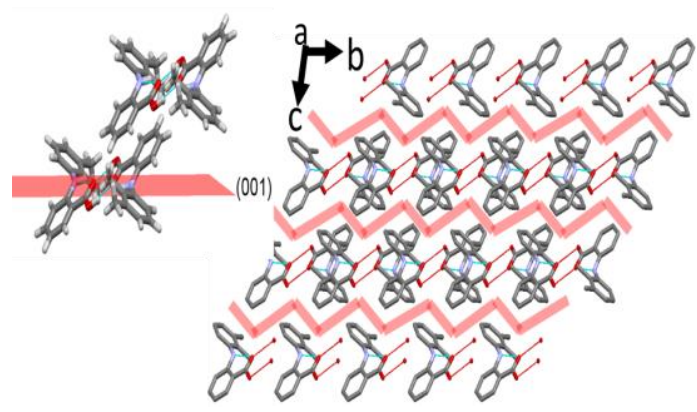

Fig. 5. The crystal packing and zigzag shape of MFA slip plane (red line).

Table 1. Identification of slip plane using visualization

\begin{tabular}{lcccc}
\hline Material & CCDC code & $\begin{array}{c}\text { Hydrogen } \\
\text { bond type }\end{array}$ & $\begin{array}{c}\text { Slip plane } \\
\text { identification }\end{array}$ & $\begin{array}{c}\text { Slip plane } \\
\text { topology }\end{array}$ \\
\hline MFA & XYANAC & 2D & 001 & Zigzag \\
MFA-NIC & EXAQOK & 3D & 001 & flat \\
\hline
\end{tabular}


On the other hand, the MFA-NIC cocrystal crystal lattice, as shown in Fig. 6, had the weakest plane parallel to (001) allowing the occurrence of a straight/flat slip plane. Referring to previous studies, a structure that has a straight/flat slip plane allows its molecules to perform lateral displacement properly due to unlimited molecular folds [30]. As a result, the tablet strength of MFA-NIC cocrystal was higher than MFA.

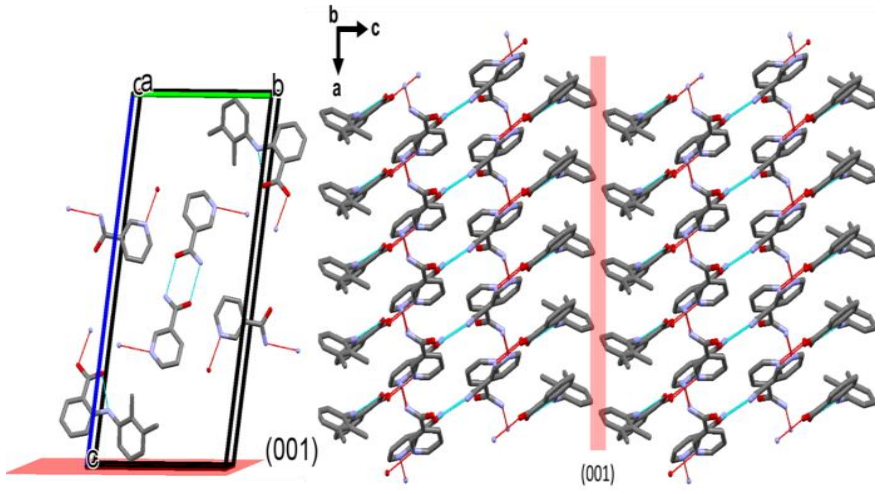

Fig. 6. The crystal packing and flat shape of MFA-NIC slip plane (red line)

In short, this research presents a deep understanding of the improvement of the mechanical properties of MFA by cocrystallization with nicotinamide conformer which has the potential for further exploration in the field of solid-state development as a new solid-state material.

\section{Conclusion}

This study showed that the different mechanical properties of MFA and MFA-NIC cocrystal were due to different crystal packings. MFA crystals contained zigzag slip plane that exhibited low plasticity. On the other hand, the higher plasticity of MFA-NIC cocrystal was due to flat slip plane, resulting in better mechanical properties such as tabletability and potential to be developed as new solid-state material. In addition, these results also showed the importance of understanding the relationship between crystal structure and its mechanical properties, particularly in cocrystallization technology.

\section{References}

1. N. Qiao, L. Mingzhong, W. Schlindwein, N. Malek, N. Davies, G. Trappit, Pharmaceutical Cocrystal: An Overview, Int. J. Pharm. (2011) 1-11.

2. T. Ranjit, A. Delori, W. Jones, M. P. Lipert, L. Roy and N. Rodriguez-Hornedo, Pharmaceutical cocrystal and poorly soluble drugs, Int. J. Pharm. (2013) 1-24.

3. N. Blagden, D. Matas, M. Gavan, P. T., York, P, Crystal engineering of active pharmaceutical ingredients to improve solubility and dissolution rates, Adv. Drug. Deliv. Rev. (2007) 617-30.

4. D.D. Gadade and S.S. Pekamwar, Pharmaceutical cocrystals: Regulatory and strategic aspects, design and development, Adv Pharm. Bull. (2016) 479-494.
5. Nijhawan, A. Monika, P. R. Santhosh, B. Sathesh and C.V.S Subrahmanyam., Solid state manipulation of lornoxicam for cocrystal-physicochemical characterization, Drug Dev. Ind. Pharm. (2013) 1-10.

6. Patole, Tanvee and D. Ashwini, Co-crystallization a technique for solubility enhancement, Int. J. Pharm. Sci. Res. (2014) 3566-3576.

7. S. Emami, M. S. Shadbad, K. Adibkia. M. B. Jalali, Recent advances in improving oral drug bioavailability by cocrystals, Bioimpacts. (2018) 305-320.

8. Z. Rahman, C. Agarabi, A. S. Zidan, S. R. Khan, A.M. Khan, Physico-mechanical and stability evaluation of carbamazepine cocrystal with nicotinamide, AAPS Pharm. Sci. Tech. (2011) 693704.

9. D. Setyawan, A. Paramanandana, V. E. Erfadrin, R. Sari, D.P. Paramita, Compression force effect on characteristics of loratadine-succinic acid cocrystal prepared by slurry method, J Res. Pharm. (2020) 410-414

10. A. V. Trask, W. D. Motherwell, W. Jones, Physical stability enhancement of theophylline via cocrystallization, Int. J. Pharm (2006) 114-123

11. O. D. Putra, D. Umeda, Y. P. Nugraha, T. Furuishi, H. Nagase, K. Fukuzawa, H. Uekusa, E. Yonemochi, Solubility improvement of epalrestat by lapisaned structure formation via cocrystallization, Cryst. Eng. Comm (2017) 2614-2622.

12. P. Shanpui, N. R. Gound, U. B. R. Khandavilli, A. Nangia, Fast dissolving curcumin cocrystal. Cryst. Growth. Des (2011) 41354145.

13. P. P. Bag, M. Chen, C. C. Sun, C. M. Reddy, Direct correlation among crystal structure, mechanical behaviour and tabletability in a trimorphic molecular compound, Cryst. Eng. Comm. (2012) 3865-3867.

14. C. C. Sun and Y. H. Kiang., On the identification of slip planes in organic crystals based on attachment energy calculation, J. Pharm. Sci. (2008) 3456-3461.

15. C. C. Sun, D. J. W. Grant, Influence of crystal structure on the tableting properties of sulfamerazine polymorphs, Pharm. Res. (2001) 274-280

16. C. C. Sun CC, H. Hou, Improving mechanical properties of caffeine and methyl gallate crystals by cocrystallization, Cryst. Growth. Des (2008) 1575-1579.

17. C. C. Sun, D. J. W. Grant, Improved tableting properties of phydroxybenzoic acid by water of crystallization: A molecular insight, Pharm. Res (2004) 382-386.

18. Y. Feng, D. J. W. Grant, Influence of crystal structure on the compaction properties of n-alkyl 4-hydroxybenzoate esters (parabens), Pharm. Res. (2006) 1608-1616

19. K. S. Khomane P. K. More, G. Raghavendra A. K. Bansal, Molecular understanding of the compaction behaviour of indomethacin polymorphs, Mol. Pharm. (2013) 631-639.

20. P. Upadhyay, K.S. Khomane L. Kumar, A. K. Bansal, Relationship between crystal structure and mechanical properties of ranitidine hydrochloride polymorphs, Cryst. Eng. Comm (2013) 3959-3964.

21. D. P. Kale, V. Puri. A. Kumar and A. K. Bansal, The role of crystallization-mediated altered crystallographic properties on the tableability of rivaroxaban and malonic acid, Pharmaceutics. (2020) 546-568.

22. A. B. Bani-Jaber, I. Hamdan. B. Al-Khaidi, Sodium mefenamate as a solution for the problems of mefenamic acid formulation and dissolution, Chem. Pharm. Bull. (2007) 1136 - 1140. 
23. L. Fabian, N. Hamill, K. S. Eccles, R. Moynihan, L. McCausland S. E. Lawrence et al., Cocrystal of fenamic acids with nicotinamide, Cryst. Growth. Des. (2011) 3522-3528.

24. D. Utami, I. Nugrahani, S. Ibrahim, Mefenamic acid-nicotinamide co-crystal synthesized by using melt crystallization method and its solubility study, Asian Journal of Pharmaceutical and Clinical Research. (2016) $135-139$.

25. G. Alderborn, C. Nystrom, Pharmaceutical powder compaction technology, $1^{\text {st }}$ edition, New York, Marcel Dekker, 377.

26. O. A. Saputra, Kurnia, S. Pujiasih, V. N. Rizki, B. Nurhayati, E. Pramono and C. Purnawan, Silylated-montmorillonite as coadsorbent of chitosan composites for methylene blue dye removal in aqueous solution, Commun. Sci. Technol. (2020) 45-52.

27. E. Taer, L. Pratiwi, A. Apriwandi, W. S. Mustika, R. Taslim and A. Agustino, Three-dimensional pore structure of activated carbon monolithic derived from hierarchically bamboo stem for supercapacitor application, Communications in Science and Technology. (2020) 22-30.

28. S. Grangeon, F. Claret, Y. Linard, C. Chiabaerge, X-ray diffraction: a powerful tool to probe and understand the structure of nanocrystalline calcium silicate hydrates. Acta. Cryst. (2013) 465-473.

29. H. Ahmed, M. R. Shimpi, S. P. Velaga, Relationship between mechanical properties and crystal structure in cocrystal and salt o paracetamol, Drug Dev. Ind. Pharm. (2016) 89-97.

30. M. H. Shariare, F. J. J. Leusen, M. D. Matas, P. York, J. Anwar, Prediction of the mechanical behaviour of crystalline solids, Pharm. Res. (2011) 319-331. 